\title{
Indeterminate thyroid cytology: detecting malignancy using analysis of nuclear images
}

\author{
Caroline Y Hayashi ${ }^{1, *}$, Danilo T A Jaune ${ }^{1, *}$, Cristiano C Oliveira², Bárbara P Coelho ${ }^{3}$, Hélio A Miot ${ }^{4}$, \\ Mariângela E A Marques ${ }^{2}$, José Vicente Tagliarini ${ }^{5}$, Emanuel C Castilho ${ }^{5}$, Carlos S P Soares ${ }^{5}$, Flávia R K Oliveira ${ }^{1}$, \\ Paula Soares ${ }^{6,7,8}$ and Gláucia M F S Mazeto(D) 1 \\ 'Department of Internal Medicine, Botucatu Medical School, Sao Paulo State University (Unesp), Botucatu, São Paulo, Brazil \\ 2Department of Pathology, Botucatu Medical School, Sao Paulo State University (Unesp), Botucatu, São Paulo, Brazil \\ ${ }^{3}$ Department of Surgery and Orthopedics, Botucatu Medical School, Sao Paulo State University (Unesp), Botucatu, São Paulo, Brazil \\ ${ }^{4}$ Department of Dermatology, Botucatu Medical School, Sao Paulo State University (Unesp), Botucatu, São Paulo, Brazil \\ ${ }^{5}$ Department of Otolaryngology and Head and Neck Surgery, Botucatu Medical School, Sao Paulo State University (Unesp), Botucatu, São Paulo, Brazil \\ ${ }^{6}$ Instituto de Investigação e Inovação em Saúde (i3S), Universidade do Porto, Porto, Portugal \\ ${ }^{7}$ Cancer Signaling and Metabolism Group, Institute of Molecular Pathology and Immunology of the University of Porto (IPATIMUP), Porto, Portugal \\ ${ }^{8}$ Department of Pathology, Medical Faculty of the University of Porto, Porto, Portugal
}

Correspondence should be addressed to G M F S Mazeto: g.mazeto@unesp.br

*(C Y Hayashi and D T A Jaune contributed equally to this work)

\begin{abstract}
Background: Thyroid nodules diagnosed as 'atypia of undetermined significance/ follicular lesion of undetermined significance' (AUS/FLUS) or 'follicular neoplasm/ suspected follicular neoplasm' (FN/SFN), according to Bethesda's classification, represent a challenge in clinical practice. Computerized analysis of nuclear images (CANI) could be a useful tool for these cases. Our aim was to evaluate the ability of CANI to correctly classify AUS/FLUS and FN/SFN thyroid nodules for malignancy.

Methods: We studied 101 nodules cytologically classified as AUS/FLUS $(n=68)$ or FN/SFN $(n=33)$ from 97 thyroidectomy patients. Slides with cytological material were submitted for manual selection and analysis of the follicular cell nuclei for morphometric and texture parameters using Image software. The histologically benign and malignant lesions were compared for such parameters which were then evaluated for the capacity to predict malignancy using the classification and regression trees gini model. The intraclass coefficient of correlation was used to evaluate method reproducibility. Results: In AUS/FLUS nodule analysis, the benign and malignant nodules differed for entropy $(P<0.05)$, while the FN/SFN nodules differed for fractal analysis, coefficient of variation (CV) of roughness, and CV-entropy $(P<0.05)$. Considering the AUS/FLUS and FN/SFN nodules separately, it correctly classified 90.0 and $100.0 \%$ malignant nodules, with a correct global classification of 94.1 and $97 \%$, respectively. We observed that reproducibility was substantially or nearly complete (0.61-0.93) in 10 of the 12 nuclear parameters evaluated.

Conclusion: CANI demonstrated a high capacity for correctly classifying AUS/FLUS and FN/SFN thyroid nodules for malignancy. This could be a useful method to help increase diagnostic accuracy in the indeterminate thyroid cytology.
\end{abstract}
Key Words
- cell nucleus
- cytology
- diagnosis
- photography
- thyroid neoplasms

https://ec.bioscientifica.com

https://doi.org/10.1530/EC-20-0648 (c) 2021 The authors Published by Bioscientifica Ltd

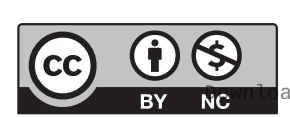

This work is licensed under a Creative Commons Attribution-NonCommercial 4.0 International License. ded from Bioscientifica.com at 04/26/2023 01:27:53PM
Endocrine Connections (2021) 10, 707-714 


\section{Introduction}

Thyroid cancer is the commonest endocrine neoplasia and its frequency is increasing (1). The method of choice for diagnosing these lesions is fine-needle aspiration (FNA), with cytological analysis performed using the Bethesda classification system (2). Despite this system has proven extremely valid and reliable (3), a considerable number of cases still have an indeterminate cytological diagnosis. Of these, 'atypia of undetermined significance/follicular lesion of undetermined significance (AUS/FLUS)' and 'follicular neoplasm/suspicious for a follicular neoplasm (FN/SFN)' categories are of particular concern as they are relatively frequent and widely vary in terms of malignancy prediction. In fact, malignancy rates of between 5 and $81 \%$ for AUS/FLUS and 11 and $65.7 \%$ for FN/SFN nodules have been reported (4).

Thus, studies using techniques with varying degrees of complexity and cost have been conducted to clarify the nature of AUS/FLUS and FN/SFN thyroid lesions, such as those using molecular techniques (5). However, this methodology is not yet available to most populations. Thus, more accessible diagnostic methods have been studied, such as those that use morphological aspects. The presence of nuclear atypia, for example, has proven significant in differentiating between benign and malignant tumors (4) and represents a good indicator of malignancy in nodules with indeterminate cytological diagnosis (6). The problem emerging from this approach is the heterogeneity of the criteria used to define the presence of nuclear atypia (6), as well as other morphological parameters, and the expected interobserver variation.

In this sense, the evaluation of nuclear morphometric and textural parameters by computerized image analysis has been successfully used in tumor tissues from different neoplasias, including thyroid (7), proving to be an accessible, reproducible and low-cost tool. Although other studies have used this technique on thyroid cytological material $(8,9,10,11,12,13)$, in general, they have not focused on the indeterminate category. In addition, sample numbers have been modest and some of the methodologies are too complex and costly (14).

We hypothesized that computerized analysis of nuclear images (CANI) is able to select cytologically indeterminate lesions for malignancy. The aim of this study was to evaluate the ability of CANI to correctly classify cytological material from AUS/FLUS and FN/SFN thyroid nodules for malignancy.

\section{Materials and methods}

\section{Design, patients and histological/cytological material processing}

This cross-sectional study evaluated cytological material from AUS/FLUS and FN/SFN thyroid nodules using CANI from follicular cells. Various nuclear morphometric and textural parameters were evaluated and compared with the final histological diagnosis of benignity or malignancy.

Stored cytological material was studied from 101 nodules cytologically classified as AUS/FLUS and FN/SFN from 97 patients consecutively submitted to thyroidectomy between 2009 and 2017. There were 87 women and 10 men with a median age (25th and 75 th percentiles) of 58 $(48.5 ; 61.5)$ years and the largest nodule diameter of 1.5 $(1.0 ; 3.0) \mathrm{cm}$. Sixty-eight patients presented AUS/FLUS and 32 presented FN/SFN nodules (three patients had nodules of both classes and one patient presented two FN/ SFN nodules). Thus, in total, 68 (67.3\%) AUS/FLUS and 33 (32.7\%) FN/SFN nodules were studied.

Two experienced pathologists (M E A M and C C O) reviewed all the slides containing the cytological material stained with Giemsa and the respective histological samples stained with hematoxylin-eosin (HE). Cytological diagnosis was classified as either AUS/FLUS or FN/SFN and histopathological as either benign or malignant according to recommendations $(2,15)$.

\section{Ethical aspects}

This study was approved by the Research Ethics Committee of Botucatu School of Medicine - Unesp - under protocol number 1.622.593, issued on 5 July 2016 (CAAE: 56858616.9.0000.5411). Consent was not required.

\section{Image acquisition and analysis}

Cytological slides were scanned and photographed (43x magnification; PANORAMIC MIDI II - 3D Histech, Japan; http://3dhistech.com/pannoramic_midi) to obtain two to three photos of the areas with the largest number of follicular cell nuclei, avoiding regions with overlapping, clustered or fragmented nuclei (8). The best photograph from each slide was chosen for analysis, according to the opinion of two experienced pathologists (MEAM and $\mathrm{CCO}$ ) and randomly numbered.

The captured images were evaluated using free software (Image J; https://imagej.nih.gov/ij/) by two researchers

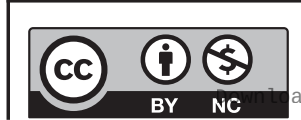

This work is licensed under a Creative Commons Attribution-NonCommercial 4.0 International License. ded from Bioscientifica.com at 04/26/2023 01:27:53PM 
who did not know the final histopathological diagnosis (blinded analysis). The program converts the color image to one containing 256 shade grayscale (16 bits), allowing better chromatin analysis and attenuating color differences between samples. Careful manual tracing of the boundaries of each nucleus in the digitized image was performed using drawing tools, followed by data extraction (Fig. 1). The number of nuclei to be evaluated in each photo was determined through a pilot statistical study that estimated the minimum quantity from which the addition of more nuclei would not alter the subsequent statistical analysis. This study was based on the standard error stabilization of $5 \%$ for each variable, concluding that 60 nuclei per photo would be sufficient and thus warranting the precision of the measures, independently of the sampled area (7). As the nuclear contour of photographs containing cytological material is performed manually and could lead to interobserver differences, method reproducibility was tested by analyzing 20 slides by both evaluators.

For each selected nucleus, the program supplied a list of morphometric and textural parameters from which the most relevant for performing nuclear evaluation were chosen, according to the previously described $(10,16)$. Thus, morphometric evaluation included primary parameters such as area, perimeter, circularity, largest diameter (feret), and the ratio between largest and smallest diameter (aspect ratio, AR). The textural evaluation included mean, median, and S.D. of greyscale (STDEV), expressed in a 256 shade grayscale, in which higher numbers mean lighter nuclei $(0=$ black; $255=$ white $)$, and roughness (RA), solidity, fractal dimension (fractal) and entropy, which measure the regularity of the grayscale distribution. Secondary indicators

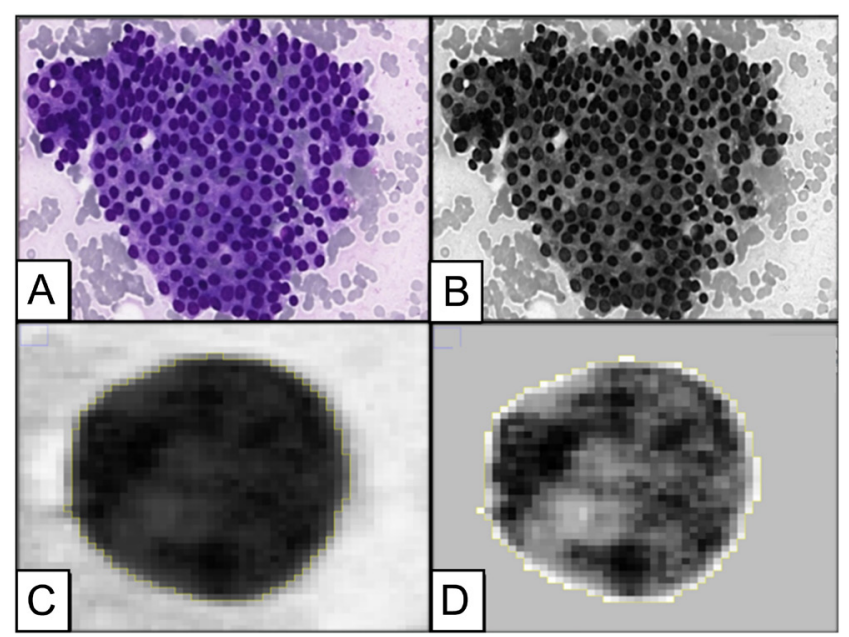

Figure 1

Photograph of cytologic smear under analysis by Image J program. (A) color photo; (B) grayscale photo; (C) and (D) selected nucleus. were also considered, such as coefficient of variation (CV) of area, CV-mean intensity, CV-STDEV, CV-perimeter, CV-circularity, CV-feret, CV-median intensity, CV-AR, CV-round, CV-solidity, CV-fractal, CV-entropy and CV-RA. The program expresses these parameters in pixels, which can then be converted into microns ( $\mu \mathrm{m})(7)$.

\section{Comparison and classification of the lesions}

The lesions with benign and malignant final histological diagnoses were compared using the above nuclear cytological parameters. The cytological material was subsequently classified for malignancy using a regression model. This classification was then compared for the final histological diagnosis with the aim of evaluating the diagnostic capacity of the method.

\section{Statistical analysis}

Collected data were submitted to statistical analysis using SPSS/Windows (version 21). Numerical variables were described by medians and quartiles (p25-p75) and the Mann-Whitney and Tukey tests were used. Patient gender was described as a numerical value and percentage and the Fisher exact test was used. The adopted level of significance was $5.0 \%$.

Based on the cytological nuclear parameters, the tumors were classified using the CRT (classification and regression tree) regression model with the gini algorithm, allowing the construction of a predictive classification tree, which starts from a root and branches from nodes that use cut-offs for the analyzed parameters provided by the model itself (17). Initially, a classification tree was prepared with all AUS/FLUS and FN/SFN nodules for malignancy and benignity, using STDEV as the initial and median as the final parameter. Then, the AUS/FLUS and FN/SFN nodules were analyzed separately by constructing a classification tree for each cytological class. In these last two trees, the initial parameter was STDEV, with final parameters of entropy and AR in AUS/FLUS nodules, and fractal in FN/ SFN nodules. Validity of the classification method was determined by calculating sensitivity, specificity, positive predictive value (PPV), negative predictive value (NPV), accuracy and area under the receiver operator characteristic (ROC) curve (AUC). The reproducibility was tested using the intraclass correlation coefficient (ICC). Sixty nuclei from each of the 20 randomly chosen slides were analyzed by both evaluators. In this statistical tool, reliability can be classified as absent (0), poor (0.01-0.19), weak (0.20-0.39),

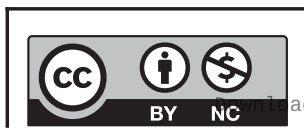

This work is licensed under a Creative Commons Attribution-NonCommercial 4.0 International License. ded from Bioscientifica.com at 04/26/2023 01:27:53PM 
moderate (0.30-0.59), substantial (0.60-0.79) and almost complete $(\geq 0.80)(18,19)$.

\section{Results}

Of the studied nodules, 72 (71.3\%) were benign (28 adenomas, 17 hyperplasia, 15 colloid goiters, 10 Hashimoto's thyroiditis, 1 metaplasia and 1 parathyroid adenoma) and $29(28.7 \%)$ malignant nodules (11 follicular variants of papillary carcinoma - FVPC, 8 papillary carcinomas - PC, 5 follicular carcinomas, 4 Hürthle cell carcinomas and 1 parathyroid carcinoma). There were no cases of non-invasive follicular thyroid neoplasm with papillarylike nuclear features (NIFTP). Twenty (29.4\%) of the AUS/FLUS nodules and 9 (27.3\%) of the FN/SFN nodules were diagnosed malignant on histological analysis. Those with benign and malignant final histological diagnoses did not differ according to gender $(P=0.99)$ or to largest nodular diameter $(P=0.90)$. Patients with benign nodules were older than those with malignant nodules $(P=0.03$; Table 1$)$.

Analyzing AUS/FLUS and FN/SFN nodules together, there was a difference between benign and malignant lesions for STDEV and Entropy $(P<0.05$; Supplementary Table 1, see section on Supplementary material given at the end of this article). Isolated analysis of AUS / FLUS nodules revealed benign and malignant lesions differed only for entropy $(P<0.05$; Supplementary Table 2$)$, while FN/SFN nodules differed in fractal, CV-RA and CV-entropy $(P<0.05$; Supplementary Table 3 ). By jointly assessing AUS/FLUS and FN/SFN nodules for nuclear parameters using the CRT model (Fig. 2), correct classification of 65 (90.3\%) benign and 24 $(82.8 \%)$ malignant nodules was obtained, with a correct global classification of 89 (88.1\%) cases (Supplementary Table 4). Thus, analysis sensitivity, specificity, AUC, NPV, and accuracy were greater than $80 \%$ (Table 2).

Table 1 General data of 101 thyroid nodules in 97 patients com AUS/FLUS and FN/SFN thyroid nodules.

\begin{tabular}{|c|c|c|c|}
\hline \multirow[b]{2}{*}{ Parameter } & \multicolumn{2}{|c|}{ Final histological diagnosis } & \multirow[b]{2}{*}{$\boldsymbol{P}$} \\
\hline & Benign & Malignant & \\
\hline Patients $^{*}(n)$ & 71 & 26 & - \\
\hline $\operatorname{Men}(n(\%))^{\dagger}$ & $7(9.9)$ & $3(11.5)$ & 0.99 \\
\hline Age (years) & $59(48.9 ; 63.0)$ & $54(41.8 ; 58.8)$ & 0.03 \\
\hline Larger diameter $(\mathrm{cm})^{\ddagger}$ & $1.5(1.0 ; 3.0)$ & $1.5(0.8 ; 3.2)$ & 0.90 \\
\hline
\end{tabular}

Significance: $P<0.05$.

*Only the worst diagnosis was considered. ${ }^{\dagger}$ Fisher's exact test. ${ }^{\ddagger}$ Median (25th percentile, 75th percentile), Mann-Whitney $U$ test.

$\%$, percentage; AUS/FLUS, atypia of undetermined significance/follicular lesion of undetermined significance; $\mathrm{cm}$, centimeter; FN/SFN, follicular neoplasm/suspicious for a follicular neoplasm; $n$, number.

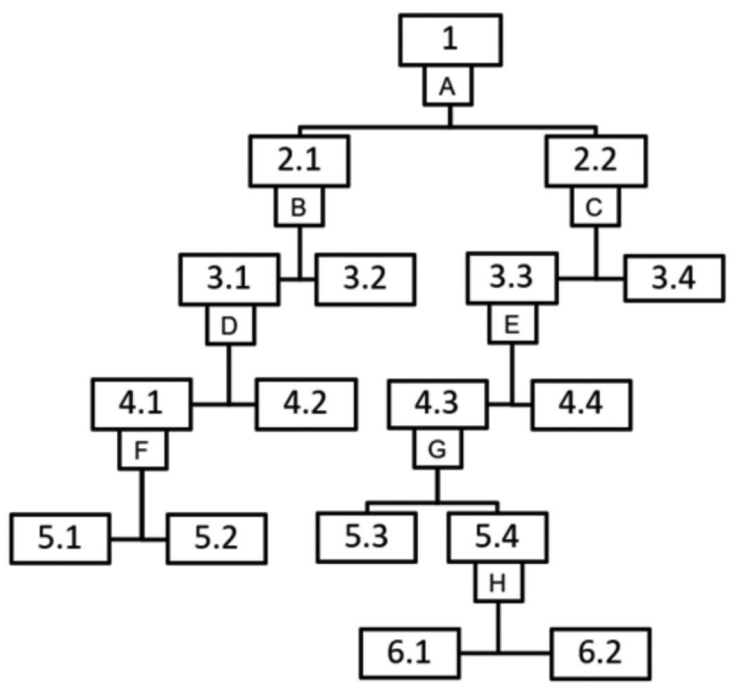

\begin{tabular}{|l|c|c|c|c|c|c|c|}
\hline \multirow{2}{*}{ Box } & \multirow{2}{*}{ Cut off } & \multicolumn{2}{c|}{ Benign } & \multicolumn{2}{c|}{ Malignant } & \multicolumn{2}{c|}{ Total } \\
\cline { 3 - 8 } & & $(\mathrm{n})$ & $(\%)$ & $(\mathrm{n})$ & $(\%)$ & $(\mathrm{n})$ & $(\%)$ \\
\hline 1-Total & & 72 & 71.3 & 29 & 28.7 & 101 & 100.0 \\
\hline A-STDEV & & & & & & & \\
\hline 2.1 & $\leq 11.145$ & 9 & 42.9 & 12 & 57.1 & 21 & 20.8 \\
\hline 2.2 & $>11.145$ & 63 & 78.8 & 17 & 21.2 & 80 & 79.2 \\
\hline B-Feret & & & & & & & \\
\hline 3.1 & $\leq 35.840$ & 9 & 56.2 & 7 & 43.8 & 16 & 15.8 \\
\hline 3.2 & $>35.840$ & 0 & 0.0 & 5 & 100.0 & 5 & 5.0 \\
\hline C-Área & & & & & & & \\
\hline 3.3 & $\leq 1383.0$ & 63 & 80,8 & 15 & 19.2 & 78 & 77.2 \\
\hline 3.4 & $>1383.0$ & 0 & 0.0 & 2 & 100.0 & 2 & 2.0 \\
\hline D-Feret & & & & & & & \\
\hline 4.1 & $\leq 30.515$ & 2 & 25.0 & 6 & 75.0 & 8 & 7.9 \\
\hline 4.2 & $>30.515$ & 7 & 87.5 & 1 & 12.5 & 8 & 7.9 \\
\hline E-Circularity & & & & & & & \\
\hline 4.3 & $\leq 0.892$ & 26 & 66.7 & 13 & 33.3 & 39 & 38.6 \\
\hline 4.4 & $>0.892$ & 37 & 94.9 & 2 & 5.1 & 39 & 38.6 \\
\hline F-Mean & & & & & & & \\
\hline 5.1 & $\leq 18.170$ & 2 & 66.7 & 1 & 33.3 & 3 & 3.0 \\
\hline 5.2 & $>18.170$ & 0 & 0.0 & 5 & 100.0 & 5 & 5.0 \\
\hline G-Fractal & & & & & & & \\
\hline 5.3 & $\leq 2.398$ & 10 & 100 & 0 & 0.0 & 10 & 9.9 \\
\hline 5.4 & $>2.398$ & 16 & 55.2 & 13 & 44.8 & 29 & 28.7 \\
\hline H-Median & & & & & & & \\
\hline 6.1 & $\leq 25.000$ & 9 & 90.0 & 1 & 10.0 & 10 & 9.9 \\
\hline 6.2 & $>25.000$ & 7 & 36.8 & 12 & 63.2 & 19 & 18.7 \\
\hline
\end{tabular}

Figure 2

Method of classification and regression trees - CRT, with gini Model, of all AUS/FLUS and FN/SFN thyroid nodules, benign or malignant, according to the cytological nuclear parameters evaluated. AUS/FLUS, atypia of undetermined significance/follicular lesion of undetermined significance; FN/SFN, follicular neoplasm/suspicious for a follicular neoplasm; STDEV, standard deviation.

When AUS/FLUS nodules were assessed separately for lesion nature using the same model (Fig. 3), 46 (95.8\%) benign and 18 (90.0\%) malignant nodules were correctly classified, with a correct overall classification of $94.1 \%$ (Supplementary Table 5). Sensitivity, specificity, PPV, NPV, accuracy and AUC were $90 \%$ or more (Table 2). In the isolated analysis of FN/SFN nodules (Fig. 4), 23 (95.8\%) benign and 9 (100\%) malignant were correctly classified, resulting in correct overall classification of 97\% (Supplementary Table 6), with specificity and PPV of $100 \%$. Sensitivity, NPV, accuracy and AUC were $90 \%$ or more (Table 2).

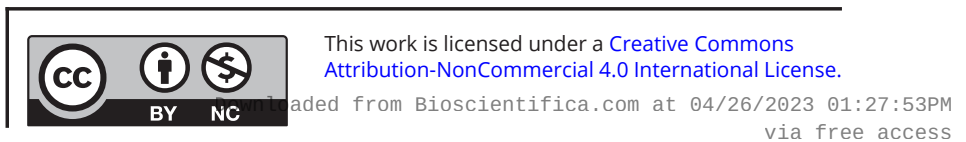


Table 2 Validity of the use of computed nuclear morphometry analysis, with the classification and regression trees (CRT) analysis, as a classificatory method.

\begin{tabular}{|c|c|c|c|}
\hline & \multicolumn{3}{|c|}{ Bethesda categories } \\
\hline & AUS/FLUS and FN/SFN & AUS/FLUS & FN/SFN \\
\hline Sensitivity (\%) & 83.0 & 90.0 & 90.0 \\
\hline Specificity (\%) & 90.0 & 95.8 & 100.0 \\
\hline PPV (\%) & 77.4 & 90.0 & 100.0 \\
\hline NPV (\%) & 93.0 & 95.8 & 95.8 \\
\hline Accuracy (\%) & 88.1 & 94.1 & 97.0 \\
\hline $\begin{array}{l}\text { Area under the } \\
\text { ROC curve }\end{array}$ & 0.86 & 0.93 & 0.95 \\
\hline
\end{tabular}

$\%$, percentage; AUS/FLUS, atypia of undetermined significance/follicular lesion of undetermined significance; FN/SFN, follicular neoplasm/ suspicious for a follicular neoplasm; NPV, negative predictive value; PPV, positive predictive value; ROC, receiver operator characteristic.

Regarding method reproducibility, almost complete agreement was observed in parameters mean, STDEV, median and circularity, substantial agreement in area, perimeter, feret, AR, fractal and entropy, and moderate agreement in solidity and RA (Table 3 ).

\section{Discussion}

CANI has proven a useful technique in the general cytohistological evaluation of thyroid nodules. However, in lesions classified by Bethesda as indeterminate and composing mainly of AUS/FLUS and FN/SFN, results have not been fully conclusive $(12,20,21)$. Recently, Valentim et al., 2018, using CANI to evaluate thyroid tumor tissues which frequently present these cytological diagnoses, observed high percentages of sensitivity and final diagnostic specificity (7). Their findings prompted us to undertake the present study in which the same tool was used to evaluate smears from thyroid nodules with indeterminate cytological diagnoses in which high percentages of correct classification regarding the real nature of the lesion were also observed.

CANI has been explored in detecting nuclear differences between colloid nodules and FVPC, between adenomatous goiter and follicular carcinoma, and even between anaplastic carcinoma and other tumors $(12,21)$. In fact, sensitivities of up to $98 \%$ have been reported in the evaluation of several thyroid lesions that included mainly classic papillary carcinoma (20). However, few authors have performed a specific cytological evaluation of AUS/ FLUS and FN/SFN nodules, the precise critical point of the Bethesda classification system. For instance, Collins $\&$ Collins, in 2013, evaluated some AUS/FLUS cases using commercial software and observed significant differences

$\begin{array}{lr}\text { https://ec.bioscientifica.com } & \text { (c) } 2021 \text { The authors } \\ \text { https://doi.org/10.1530/EC-20-0648 } & \text { Published by Bioscientifica Ltd }\end{array}$

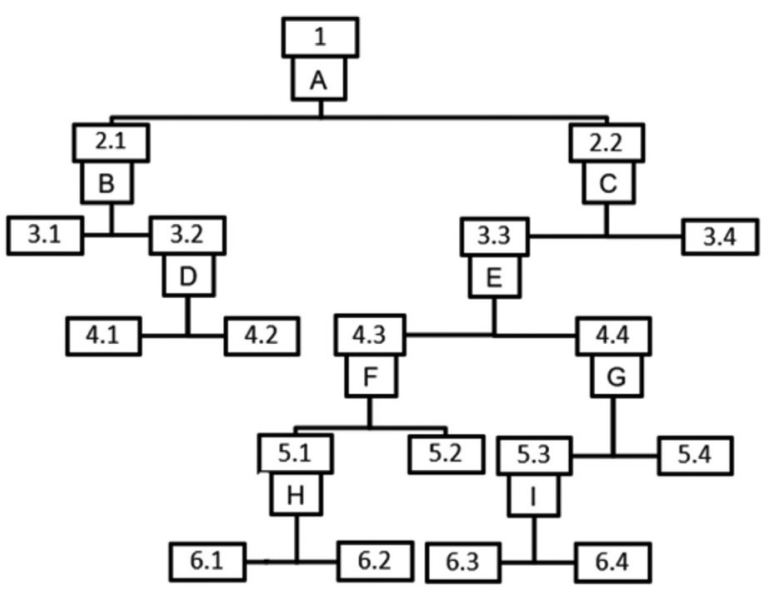

\begin{tabular}{|l|c|c|c|c|c|c|c|}
\hline \multirow{2}{*}{ Box } & \multirow{2}{*}{ Cut off } & \multicolumn{2}{c|}{ Benign } & \multicolumn{2}{c|}{ Malignant } & \multicolumn{2}{c|}{ Total } \\
\cline { 3 - 8 } & & $(\mathrm{n})$ & $(\%)$ & $(\mathrm{n})$ & $(\%)$ & $(\mathrm{n})$ & $(\%)$ \\
\hline 1-Total & & 48 & 70.6 & 20 & 29.4 & 68 & 100.0 \\
\hline A-STDEV & & & & & & & \\
\hline 2.1 & $\leq 11.145$ & 7 & 46.7 & 8 & 53.3 & 15 & 22.1 \\
\hline 2.2 & $>11.145$ & 41 & 77.4 & 12 & 22.6 & 53 & 77.9 \\
\hline B-Feret (micra) & & & & & & & \\
\hline 3.1 & $\leq 9.418$ & 1 & 14.3 & 6 & 85.7 & 7 & 10.3 \\
\hline 3.2 & $>9.418$ & 6 & 75.0 & 2 & 25.0 & 8 & 11.8 \\
\hline C-CV-RA & & & & & & & \\
\hline 3.3 & $\leq 37.169$ & 41 & 80.4 & 10 & 19.6 & 51 & 75.0 \\
\hline 3.4 & $>37.169$ & 0 & 0.0 & 2 & 100.0 & 2 & 2.9 \\
\hline D-Area & & & & & & & \\
\hline 4.1 & $\leq 1042.25$ & 6 & 100.0 & 0 & 0.0 & 6 & 8.8 \\
\hline 4.2 & $>1042.25$ & 0 & 0.0 & 2 & 100.0 & 2 & 2.9 \\
\hline E-Entropy & & & & & & & \\
\hline 4.3 & $\leq 2.428$ & 7 & 58.3 & 5 & 41.7 & 12 & 17.6 \\
\hline 4.4 & $>2.428$ & 34 & 87.2 & 5 & 12.8 & 39 & 57.4 \\
\hline F-CV-Circularity & & & & & & & \\
\hline 5.1 & $\leq 6.389$ & 7 & 77.8 & 2 & 22.2 & 9 & 13.2 \\
\hline 5.2 & $>6.389$ & 0 & 0.0 & 3 & 100.0 & 3 & 4.4 \\
\hline G-CV-Perimeter & & & & & & & \\
\hline 5.3 & $\leq 12.898$ & 12 & 70.6 & 5 & 29.4 & 17 & 25.0 \\
\hline 5.4 & $>12.898$ & 22 & 100.0 & 0 & 0.0 & 22 & 32.4 \\
\hline H-Entropy & & & & & & & \\
\hline 6.1 & $\leq 2.389$ & 7 & 100.0 & 0 & 0.0 & 7 & 10.3 \\
\hline 6.2 & $>2.389$ & 0 & 0.0 & 2 & 100.0 & 2 & 2.9 \\
\hline I-AR & & & & & & & \\
\hline 6.3 & $\leq 1.353$ & 11 & 84.6 & 2 & 15.4 & 13 & 19.1 \\
\hline 6.4 & $>1.353$ & 1 & 25.0 & 3 & 75.0 & 4 & 5.9 \\
\hline
\end{tabular}

\section{Figure 3}

Method of classification and regression trees - CRT, with gini Model, of AUS/FLUS thyroid nodules, benign or malignant, according to the cytological nuclear parameters evaluated. AR, aspect ratio; AUS/FLUS, atypia of undetermined significance/follicular lesion of undetermined significance; CV, coefficient of variation; CV-RA, coefficient of variation of roughness; STDEV, standard deviation.

between benign and malignant lesions regarding the nucleus/cytoplasm ratio (14). These findings encourage the use of computerized systems to evaluate FN/SFN thyroid lesions, as well as investigate the usefulness of other free software. Additionally, as cytoplasm seems more prone to artifacts appearing during the FNA procedure and smear execution, it would be interesting to consider whether nuclear evaluation per se would be sufficient.

In this present study, CANI was used to evaluate a considerable number of AUS/FLUS and FN/SFN thyroid nodules, and the vast majority of cases were correctly classified in relation to the final histological diagnosis.

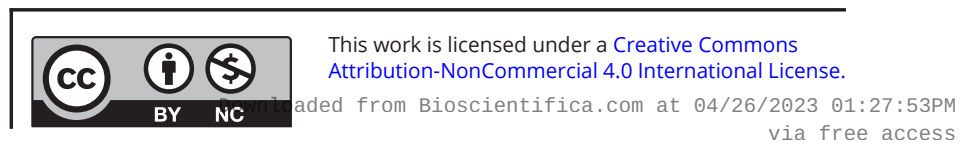




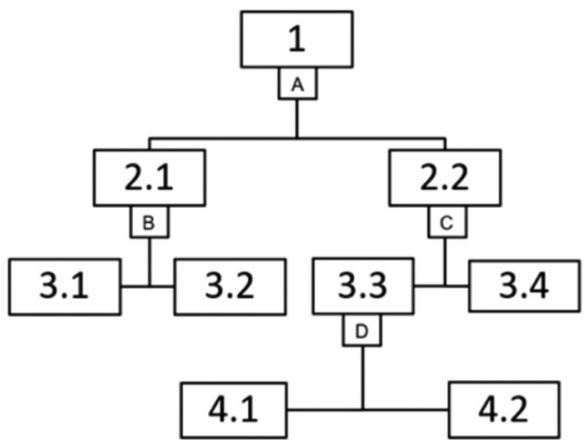

\begin{tabular}{|l|c|c|c|c|c|c|c|}
\hline \multirow{2}{*}{ Box } & \multirow{2}{*}{ Cut off } & \multicolumn{2}{c|}{ Benign } & \multicolumn{2}{c|}{ Malignant } & \multicolumn{2}{c|}{ Total } \\
\cline { 3 - 8 } & & $(\mathrm{n})$ & $(\%)$ & $(\mathrm{n})$ & & & $(\mathrm{n})$ \\
\hline 1-Total & & 24 & 72.7 & 9 & 27.3 & 33 & 100.0 \\
\hline A-STDEV & & & & & & & \\
\hline 2.1 & $\leq 11.615$ & 3 & 37.5 & 5 & 62.5 & 8 & 24.2 \\
\hline 2.2 & $>11.615$ & 21 & 84.0 & 4 & 16.0 & 25 & 75.8 \\
\hline B-CV-RA & & & & & & & \\
\hline 3.1 & $\leq 8.112$ & 0 & 0.0 & 5 & 100.0 & 5 & 15.2 \\
\hline 3.2 & $>8.112$ & 3 & 100.0 & 0 & 0.0 & 3 & 9.1 \\
\hline C-Perimeter & & & & & & & \\
\hline 3.3 & $\leq 132.175$ & 21 & 95.5 & 1 & 4.5 & 22 & 66.7 \\
\hline 3.4 & $>132.175$ & 0 & 0.0 & 3 & 100.0 & 3 & 9.1 \\
\hline D-Fractal & & & & & & & \\
\hline 4.1 & $\leq 2.531$ & 20 & 100.0 & 0 & 0.0 & 20 & 60.6 \\
\hline 4.2 & $>2.531$ & 1 & 50.0 & 1 & 50.0 & 2 & 6.1 \\
\hline
\end{tabular}

\section{Figure 4}

Method of classification and regression trees - CRT, with gini Model, of FN/SFN thyroid nodules, benign or malignant, according to the cytological nuclear parameters evaluated. CV-RA, coefficient of variation of roughness; FN/SFN, follicular neoplasm/suspicious for a follicular neoplasm; STDEV, standard deviation.

When AUS/FLUS and FN/SFN nodules were considered together in the analysis, correct global classification of $88 \%$ was obtained, with sensitivity and specificity higher than $80 \%$ in detecting malignancy. However, individual evaluation by cytological class would seem more

Table 3 Intraclass correlation coefficient, between two examiners, observed for each of the cytological nuclear parameters evaluated.

\begin{tabular}{|c|c|c|}
\hline Parameter & $\begin{array}{c}\text { Intraclass correlation } \\
\text { coefficient }\end{array}$ & $95 \% \mathrm{Cl}$ \\
\hline Area & 0.76 & $0.48-0.90$ \\
\hline Mean gray intensity & 0.93 & $0.80-0.97$ \\
\hline STDEV & 0.83 & $0.63-0.93$ \\
\hline Perimeter & 0.77 & $0.52-0.90$ \\
\hline Feret & 0.79 & $0.54-0.91$ \\
\hline Median gray intensity & 0.90 & $0.76-0.96$ \\
\hline$A R$ & 0.61 & $0.25-0.83$ \\
\hline Circularity & 0.93 & $0.83-0.97$ \\
\hline Solidity & 0.42 & $0.03-0.72$ \\
\hline RA & 0.59 & $-0.1-0.85$ \\
\hline Fractal & 0.73 & $0.44-0.89$ \\
\hline Entropy & 0.70 & $0.38-0.87$ \\
\hline
\end{tabular}

AR, aspect ratio; RA, roughness; STDEV, standard deviation of gray intensity. appropriate, as in practice, the nodule under investigation would present either AUS/FLUS or FN/SFN diagnosis and not AUS/FLUS and FN/SFN. Interestingly, these individual evaluations produced even higher percentages, with rates of 90\% or more for sensitivity, specificity, PPV, NPV, accuracy and AUC. For FN/SFN nodules, specificity and PPV reached 100\%, correctly classifying all truly malignant lesions.

An interesting finding of this study was the similarity in malignancy rates, close to 30\%, observed for AUS/ FLUS and FN/SFN nodules. Although rates below 15\% are generally attributed to the AUS/FLUS category, malignancy rates for this diagnostic class, particularly in cancer centers, have in fact been higher than previously estimated and can reach almost 38\% (22). It is very important to consider the frequency of malignancy of the institution when evaluating different diagnostic tests since this rate can influence the percentages related to the performance of these tests (6).

Limitations of this study could be possible interobserver variability in results using this method, the time required for nuclear image analysis, the number of nodes required for the design and size of the classification trees, as well the lack of NIFTP cases, and the sample size. In regard to inter-observer variability, we observed high reproducibility levels using CANI in this study as there was almost complete agreement between both evaluators in 10 of the 12 parameters analyzed (7). However, the model was not validated for the entire cohort of patients in order to test that reproducibility. Furthermore, it would be of interest to see if the developed model remains highly accurate in predicting malignancy if used on a new cohort of patients in the same institution, and even more importantly, to see the validation of the model for a cohort of patients from an outside institution. Regarding the time required for nuclear analysis, it varies according to individual experience, decreasing as experience increases, up to about $30 \mathrm{~min} /$ case (7). As for the number of nodes and classification tree size, very large trees with numerous nodes can be associated with overfitting and a lack of explanatory power (7). This did not prove to be a significant problem in this study as both the number of nodes and tree sizes could only be considered small to moderate. As for sample size, it could have been larger. However, it was sufficient to allow developing evaluation algorithms which can be tested on bigger samples in the future. Studies with larger samples would probably include NIFTP cases (23), which were not found in our group of patients and could have nuclear alterations but turn out to be 'non-malignant' in the final histological examination. In this sense, we compared recently the histological

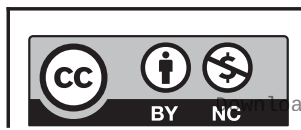

This work is licensed under a Creative Commons Attribution-NonCommercial 4.0 International License. ded from Bioscientifica.com at 04/26/2023 01:27:53PM 
material of NIFTP, infiltrative FVPC, and encapsulated/ well-demarcated FVPC with tumor capsular invasion, using CANI and observed nuclear textural differences between NIFTP and infiltrative FVPC but not between the former and encapsulated/well-demarcated FVPC (24). In addition to significantly larger samples, it would also be interesting to apply this model to other Bethesda categories, such as benign. Thus, further studies are needed to address these issues.

Despite the above-mentioned limitations, this study has the merit of having developed models to aid in predicting malignancy in AUS/FLUS and FN/SFN thyroid nodules. This easily accessible, inexpensive, and reproducible methodology could be a useful diagnostic support tool in evaluating lesions of indeterminate cytological diagnosis.

In conclusion, our study showed that computerized analysis of nuclear images of cytological material, associated with statistical tree classification, can effectively classify AUS/FLUS and FN/SFN thyroid nodules for malignancy.

\section{Supplementary materials}

This is linked to the online version of the paper at https://doi.org/10.1530/ EC-20-0648.

\section{Declaration of interest}

The authors declare that there is no conflict of interest that could be perceived as prejudicing the impartiality of the research reported.

\section{Funding}

This study received financial support from Fundação de Amparo à Pesquisa do Estado de São Paulo (FAPESP; processes number 2016/149870 and number 2016/14988-6). Further funding through 'Fundação para a Ciência e Tecnologi' - FCT and FEDER 'Fundo Europeu de Desenvolvimento Regional funds through the COMPETE 2020'; by Operacional Programme for Competitiveness and Internationalization 'POCl' (Grant no. POCl01-0145-FEDER-007274); by the 'Advancing cancer research: from basic knowledge to application' (grant no. NORTE-01-0145-FEDER-000029); and by the 'Projetos Estruturados de I \& D \& I', funded by Norte 2020 Programa Operacional Regional do Norte.

\section{Acknowledgements}

The authors thank to Fundação de Amparo à Pesquisa do Estado de São Paulo (FAPESP; processes number 2016/14987-0 and number 2016/14988-6).

\section{References}

1 Veiga LH, Neta G, Aschebrook-Kilfoy B, Ron E \& Devesa SS. Thyroid cancer incidence patterns in Sao Paulo, Brazil, and the U.S. SEER program, 1997-2008. Thyroid 201323 748-757. (https://doi. org/10.1089/thy.2012.0532)
2 Cibas ES \& Ali SZ. The 2017 Bethesda system for reporting thyroid cytopathology. Thyroid 201727 1341-1346. (https://doi.org/10.1089/ thy.2017.0500)

3 Bongiovanni M, Spitale A, Faquin WC, Mazzucchelli L \& Baloch ZW. The Bethesda system for reporting thyroid cytopathology: a meta-analysis. Acta Cytologica 201256 333-339 (https://doi. org/10.1159/000339959).

4 Lim JXY, Nga ME, Chan DKH, Tan WB, Parameswaran R \& Ngiam KY. Subclassification of Bethesda atypical and follicular neoplasm categories according to nuclear and architectural atypia improves discrimination of thyroid malignancy risk. Thyroid 201828 511-521. (https://doi.org/10.1089/thy.2017.0274)

5 Patel KN, Angell TE, Babiarz J, Barth NM, Blevins T, Duh QY, Ghossein RA, Harrell RM, Huang J, Kennedy GC, et al. Performance of a genomic sequencing classifier for the preoperative diagnosis of cytologically indeterminate thyroid nodules. JAMA Surgery 2018153 817-824. (https://doi.org/10.1001/jamasurg.2018.1153)

6 Valdebarrano P, Khazai L, Thompson ZJ, Sharpe SC, Tarasova VD, Otto KJ, Hallanger- Johnson JE, Wadsworth JT, Wenig BM, Chung CH, et al. Cancer risk associated with nuclear atypia in cytologically indeterminate thyroid nodules: a systematic review and metaanalysis. Thyroid 201828 210-219. (https://doi.org/10.1089/ thy.2017.0419)

7 Valentim FO, Coelho BP, Miot HA, Hayashi CY, Jaune DTA, Oliveira CC, Marques MEA, Tagliarini JV, Castilho EC, Soares P, et al. Follicular thyroid lesions: is there a discriminatory potential in the computerized nuclear analysis? Endocrine Connections 20187 907-913. (https://doi.org/10.1530/EC-18-0237)

8 Gupta N, Sarkar C, Singh R \& Karak AK. Evaluation of diagnostic efficiency of computerized image analysis based quantitative nuclear parameters in papillary and follicular thyroid tumors using paraffinembedded tissue sections. Pathology Oncology Research 2001 74-55. (https://doi.org/10.1007/BF03032605)

9 Kelman AS, Rathan A, Leibowitz J, Burstein DE \& Haber RS. Thyroid cytology and the risk of malignancy in thyroid nodules: importance of nuclear atypia in indeterminate specimens. Thyroid 200111 271-277. (https://doi.org/10.1089/105072501750159714)

10 Elsheikh TM, Asa SL, Chan JK, DeLellis RA, Heffess CS, LiVolsi VA \& Wenig BM. Interobserver and intraobserver variation among experts in the diagnosis of thyroid follicular lesions with borderline nuclear features of papillary carcinoma. American Journal of Clinical Pathology 2008130 736-744. (https://doi.org/10.1309/AJCPKP2QUVN4RCCP)

11 Lubitz CC, Faquin WC, Yang J, Mekel M, Gaz RD, Parangi S, Randolph GW, Hodin RA \& Stephen AE. Clinical and cytological features predictive of malignance in thyroid follicular neoplasms. Thyroid 201020 25-31. (https://doi.org/10.1089/thy.2009.0208)

12 Priya SS \& Sundaram S. Morphology to morphometry in cytological evaluation of thyroid lesions. Journal of Cytology 201128 98-102. (https://doi.org/10.4103/0970-9371.83462)

13 Yashaswini R, Suresh TN \& Sagayaraj A. Cytological evaluation of thyroid lesions by nuclear morphology and nuclear morphometry. Journal of Cytology 201734 197-202. (https://doi.org/10.4103/JOC. JOC_87_16)

14 Collins BT \& Collins LE. Assessment of malignancy for atypia of undetermined significance in thyroid fine-needle aspiration biopsy evaluated by whole-slide image analysis. American Journal of Clinical Pathology 2013139 736-745. (https://doi.org/10.1309/ AJCPQU29GHXYSZRR)

15 Lloyd RV, Osamura RY, Kloppel G \& Rosai J. WHO Classification of Tumours of Endocrine Organs, 4th ed. Lyon, France: IARC Press, 2017.

16 Crissman JD, Drozdowicz S, Johnson C \& Kini SR. Fine needle aspiration diagnosis of hyperplastic and neoplastic follicular nodules of the thyroid - a morphometric study. Analytical and Quantitative Cytology and Histology $1991 \mathbf{1 3} 321-328$.

17 Loh W-Y. Classification and regression trees. WIREs Data Mining and Knowledge Discovery 2011 14-23. (https://doi.org/10.1002/widm.8) https://ec.bioscientifica.com

https://doi.org/10.1530/EC-20-0648 (c) 2021 The authors Published by Bioscientifica Ltd
This work is licensed under a Creative Commons Attribution-NonCommercial 4.0 International License. ded from Bioscientifica.com at 04/26/2023 01:27:53PM 
18 Lee KM, Lee J, Chung CY, Ahn S, Sung KH, Kim TW, Lee HJ \& Park MS. Pitfalls and important issues in testing reliability using intraclass correlation coefficients in orthopaedic research. Clinics in Orthopedic Surgery 20124 149-155. (https://doi.org/10.4055/ cios.2012.4.2.149)

19 Miot HA. Agreement analysis in clinical and experimental trials. Jornal Vascular Brasileiro 201615 89-92. (https://doi.org/10.1590/16775449.004216)

20 Harms H, Hofmann M \& Ruschenburg I. Fine needle aspiration of the thyroid: can an image processing system improve differentiation? Analytical and Quantitative Cytology and Histology 200224 147-153.

21 Zacks JF, de las Morenas A, Beazley RM \& O’Brian MJ. Fineneedle aspiration cytology diagnosis of colloid nodule versus folicular variant of papillary carcinoma of the thyroid. Diagnostic Cytopathology 199818 87-90. (https://doi.org/10.1002/(sici)10970339(199802)18:2<87::aid-dc1>3.0.co;2-q)
22 Ho AS, Sarti EE, Jain KS, Wang H, Nixon IJ, Shaha AR, Shah JP, Kraus DH, Ghossein R, Fish SA, et al. Malignancy rate in thyroid nodules classified as Bethesda category III (AUS/FLUS). Thyroid 201424 832-839. (https://doi.org/10.1089/thy.2013.0317)

23 Nikiforov YE, Seethala RR, Tallini G, Baloch ZW, Basolo F, Thompson LD, Barletta JA, Wenig BM, Al Ghuzlan A, Kakudo K, et al. Nomenclature revision for encapsulated follicular variant of papillary thyroid carcinoma: a paradigm shift to reduce overtreatment of indolent tumors. JAMA Oncology 20162 1023-1029. (https://doi. org/10.1001/jamaoncol.2016.0386)

24 Coelho BP, Valentim FO, Miot HA, Jaune DTA, Hayashi CY, Oliveira CC, Marques MA, Tagliarini JV, Castilho EC, Soares P, et al. Follicular lesions with papillary nuclear characteristics: differences in chromatin detected by computerized image analysis. Archives of Endocrinology and Metabolism 202064 630-635. (https://doi. org/10.20945/2359-3997000000282)

Received in final form 26 April 2021

Accepted 2 June 2021

Accepted Manuscript published online 2 June 2021
This work is licensed under a Creative Commons Attribution-NonCommercial 4.0 International License. ded from Bioscientifica.com at 04/26/2023 01:27:53PM via free access 